\title{
Influence of correction of flow limitation on continuous positive airway pressure efficiency in sleep apnoea/hypopnoea syndrome
}

\author{
J-C. Meurice*, J. Paquereau+, A. Denjean+, F. Patte*, F. Series $\$$
}

Influence of correction of flow limitation on continuous positive airway pressure efficiency in sleep apnoea/hypopnoea syndrome. J-C. Meurice, J. Paquereau, A. Denjean, F. Patte, F. Series. (CERS Journals Ltd 1998.

ABSTRACT: We evaluated the efficiency of two different treatment procedures with continuous positive airway pressure (CPAP) on sleep, nocturnal breathing characteristics and daytime vigilance in 18 newly diagnosed patients with untreated sleep apnoea/hypopnoea syndrome (SAHS) randomly allocated to two different groups. In group I, the positive pressure (PP) level was set to suppress flow limitation (PFL), while in group II the PP was set at a level that eliminated only apnoea/hypopnoea and snoring (PAHS). At the end of a 3 week period of home CPAP therapy, a follow-up sleep study, vigilance and cognitive tests were made.

Overall, $P$ FL was significantly higher than $P_{\text {AHS }}$ values $\left(P F L: 10.4 \pm 2.6 \mathrm{cmH}_{2} \mathrm{O}\right.$; PAHS: $8.9 \pm 2.6 \mathrm{cmH}_{2} \mathrm{O} ; \mathrm{p}<0.01$, mean $\left.\pm \mathrm{sD}\right)$. We found no difference in sleep quality, nocturnal saturation and apnoea/hypopnoea index, or in daytime vigilance tests between the two groups at the end of the treatment period. However, there was a significantly greater scattering in the changes of sleep latency in group II than in group I. This was associated with a significant difference in the daily duration of nasal CPAP use between the two groups (group I: $7.29 \pm 0.95 \mathrm{~h}^{\cdot} \cdot \mathrm{day}^{-1}$; group II: $6.01 \pm 0.94 \mathrm{~h}^{\cdot} \cdot \mathrm{day}^{-1}$; $p=0.01$ ) and with a positive correlation between final maintenance of wakefulness test values and the duration of CPAP use $(p<0.05 ; r=0.55)$.

These results tend to show that correcting flow limitation is associated with a higher observance and a more important efficiency in normalizing daytime vigilance than with conventional nasal continuous positive airway pressure.

Eur Respir J 1998; 11: 1121-1127.
*Service de Pneumologie, CHU de Poitiers, France. +'Service d'Explorations fonctionnelles, CHU de Poitiers, France. §Unité de recherche, Centre de pneumologie, Hôpital Laval, Université Laval Québec, Canada.

Correspondence: J-C. Meurice

Service de pneumologie

CHU de Poitiers

350 Avenue Jacques Coeur

86000 Poitiers

France

Fax: 33549443828

Keywords: Continuous positive airway pressure

flow limitation

sleep apnoea syndrome

treatment

Received: July 101997

Accepted after revision January 301998
Sleep apnoea/hypopnoea syndrome (SAHS) is an important public health problem leading to increases in mortality [1], the related morbidity rate of cardiovascular and cerebrovascular diseases [2], and neuropsychological dysfunctions [3, 4]. These increases in risk factors emphasize the need for an effective treatment in SAHS. The first description of the beneficial effects of nasal continuous positive airway pressure (CPAP) in the treatment of SAHS was reported by Sullvan et al. in 1981 [5], and its effectiveness is demonstrated by dramatic improvements in morbidity and mortality with CPAP therapy [6-9].

The level of the effective positive pressure $(P$ eff $)$ has been determined according to several different methods. Usually, $P$ eff level is identified during a titration sleep study and corresponds to the minimal pressure level that prevents apnoea, hypopnoea and snoring in all sleep stages and body positions. In the absence of CPAP-related side effects, such as nasal obstruction, and poor CPAP observance, the persistence of excessive daytime sleepiness during the course of CPAP therapy has led to the hypothesis that sleep could be disturbed by persisting upper airway abnormalities inducing increased respiratory efforts associated with persisting sleep fragmentation due to recurrent arousals. This pointed out the need to increase $P$ eff to the level that minimizes respiratory efforts in order to restore upper airway patency [10]. Such a pressure level should, therefore, suppress inspiratory flow limitation as assessed by the disappearance of inspiratory plateauing of the flow signal recorded with a pneumotachograph [11]. However, the clinical benefits of correcting flow limitation compared to the suppression of apnoea, hypopnoea and snoring during CPAP therapy in SAHS have never been evaluated.

Therefore, the aim of the present study was to make a prospective comparison of the efficiency of two different settings of CPAP therapy in the treatment of SAHS: the first mode corresponding to the pressure level that suppressed snoring, apnoea and hypopnoea, while the second mode corresponded to the positive pressure level that normalized these events and abolished flow limitation.

\section{Materials and methods}

\section{Patients}

Twenty three untreated male SAHS patients initially accepted the invitation to participate in this study. However, we failed to obtain complete results in five patients. 
Two of these patients could not be retained for analysis because it was impossible to adequately detect flow limitation during the titration night (see below). Two other patients later refused to carry on with the investigations following inability to tolerate the oesophageal catheter during the first titration night. The fifth patient who was allocated to the flow-limitation abolition group (see below) spontaneously interrupted CPAP treatment during the home study period due to intolerance of the mask and CPAP machine. The 18 remaining male SAHS patients who completed this study had a mean $( \pm$ SD) age of $55 \pm \quad 9$ yrs and a body mass index (BMI) of $32.9 \pm 4.5 \mathrm{~kg} \cdot \mathrm{m}^{-2}$. Twelve of them were still in active employment. Half of the 18 patients who completed the study were treated for hypertension (90\%) and diabetes (30\%). None of the patients were treated with sedative drugs and all subjects were asked to avoid alcohol during the study. The clinical diagnosis of SAHS was confirmed by an initial standard polysomnography (apnoea/hypopnoea index $(\mathrm{A} / \mathrm{HI})=$ $58.7 \pm 21.7$ events $\left.\cdot \mathrm{h}^{-1}\right)$. Daytime vigilance was quantified at baseline by maintenance of wakefulness test (MWT) [12] and psychometric tests (Trail making test) [13]. Subjective evaluation of daytime vigilance was obtained by a clinical score from the Epworth Sleep Questionnaire (ESQ) [14]. Written informed consent was obtained from each subject and the protocol was authorized by the Institutional Research Board.

\section{Sleep studies}

The polysomnographic recordings consisted of continuous acquisition of electroencephalograms (with surface electrodes placed at $\mathrm{F}_{\mathrm{Z}} / \mathrm{C}_{3}, \mathrm{C}_{3} / \mathrm{A}_{2}, \mathrm{C}_{3} / \mathrm{O}_{1}$ ), submental electromyograms, electro-oculograms, electrocardiograms, thoracoabdominal movements recorded by inductive plethysmography, and arterial oxyhaemoglobin saturation $\left(\mathrm{Sa}_{\mathrm{a}} \mathrm{O}_{2}\right)$ with a finger oximeter (N 200; Nellcor, Harward, USA). Nasal airflow was recorded with a pneumotachograph (Fleisch No. 2) fixed to a tightly fitting nasal mask and placed between the mask and the whisper swivel valve, while mouth leakage was detected with a thermistor. The oesophageal pressure was recorded using a thin catheter with a piezoelectric sensor at the distal end (Galtec, Premium Medical, France) introduced into one nostril following local anaesthesia and positioned in the lower third of the oesophagus. The tip was positioned 34-36 $\mathrm{cm}$ from the nares to obtain a tracing with the smallest amount of cardiac artifact. The occurrence of snoring was identified on the presence of fluttering of the nasal flow signal [15]. All variables were recorded on a computer (Morphée; Medatec, Belgium).

\section{Maintenance of wakefulness tests}

MWT were carried out according to previously published recommendations [12]. The patients were seated in an armchair and were asked to remain awake for as long as possible during four consecutive $40 \mathrm{~min}$ trials after the light had been turned off, every $2 \mathrm{~h}$. Each MWT was terminated as soon as the patient was clearly asleep, defined as three continuous $30 \mathrm{~s}$ epochs of stage 1 sleep or any epoch of stage 2-4 or rapid eye movement (REM) sleep. In stage 1, MWT were calculated from the third epoch in a similar manner in all patients. The mean sleep latency upon the four tests was measured.

\section{Trail making test}

This test has previously been used to evaluate brain damage [13] and requires alertness and concentration. It consists of two parts, each with 25 circles distributed over a white sheet of paper. In part A the circles are numbered from 1 to 25 . The patient was asked to draw a line connecting the circles in numerical sequence as quickly as possible. Part B includes numbers from 1 to 13 and letters from A to L. The patient was asked to alternate between numbers and letters in an ascending sequence. The score corresponded to the time needed to complete each part, including the additional correction time during each test.

\section{Study design}

Initial study. Following the acceptance to participate in the study, daytime sleepiness and cognitive function were quantified with the ESQ, MWT and trail making test. During a second polysomnographic night we determined the positive pressure levels that suppressed: 1) obstructive apnoea, hypopnoea and snoring (PAHS); and 2) flow limitation $(P \mathrm{FL})$. During the titration night, the positive pressure level was increased in steps of $1 \mathrm{cmH}_{2} \mathrm{O}$. The regression of snoring was assessed according to the disappearance of the fluttering on the inspiratory flow signal and was systematically confirmed by the technician who was in attendance. Respiratory cycles were classified as flow-limited according to a breath-by-breath analysis when the nasal inspiratory flow signal became maximal and plateaued while the oesophageal pressure still increased [16]. Both levels were determined during the first sleep cycle that included REM sleep, by one of the authors, while the patients were in supine position. During the rest of the titration night, the pressure level was increased until not more than three consecutive respiratory cycles with snoring or flow limitation were observed.

Patients were then randomly allocated to two different groups that were paired for age, apnoea/hypopnoea index and MWT sleep latency. The two groups differed in $P$ eff level that was used during the study period: in group I, $P$ eff was fixed at PFL level; and in group II $P$ eff was fixed at $P$ AHS level. The patients were unaware of the group that they were allocated to.

Final study. After a 3 week period of home treatment with the CPAP apparatus, at a Peff level that depended on the group they were randomly allocated to, all patients had a follow-up polysomnographic recording while wearing the CPAP apparatus as used during the last 3 week period without any modification in the pressure characteristics. The ESQ, MWT and trail making tests were performed during the day following this last polysomnographic recording. 


\section{Data collection and statistical analysis}

Polysomnographic recordings were visually interpreted in $30 \mathrm{~s}$ epoch by the same neurophysiologist, who was blind to the $P$ eff level used by the patients. Sleep parameters were determined according to the criteria of RECHTSCHAFFEN and KALES [17] with stages I and II combined in light sleep (LS), and stages III and IV combined in slow wave sleep (SWS). The number of arousals per hour [18] was obtained. Apnoea was defined as the cessation of nasal-oral airflow for at least $10 \mathrm{~s}$. Hypopnoea was defined as more than a $50 \%$ decrease in the nasal-oral airflow for at least $10 \mathrm{~s}$ associated with a $4 \%$ drop in $\mathrm{Sa}_{\mathrm{a}} \mathrm{O}_{2}$ and/or an arousal. Type of apnoea and hypopnoea (obstructive, mixed or central) was defined according to the pattern of oesophageal pressure swings throughout the event. Three $\mathrm{Sa}_{\mathrm{O}} \mathrm{O}_{2}$ variables were studied: 1$)$ awake $\left(\mathrm{Sa}_{\mathrm{a}} \mathrm{O}_{2}, \mathrm{w}\right)$ that corresponded to the average value of the first 10 min recording during wakefulness; 2) mean $\left(\mathrm{Sa}_{\mathrm{a}} \mathrm{O}_{2}, \mathrm{~m}\right)$ was the average value during all night recording; and 3$)$ minimal $\left(\mathrm{Sa}, \mathrm{O}_{2}, \mathrm{~min}\right)$ was the lowest value obtained during the night. For each polysomnographic study the number of flow limited cycles per hour was determined. During the final polysomno-graphy, we studied the effect of flow limitation on sleep fragmentation and respiratory effort. We simultaneously analysed arousals [18], micro-arousals (defined as an in-trusion of alpha rhythm for 1-3 s) in order to explore micro-architecture, and the oesophageal pressure value (maximal and mean values) during 30 periods of $1 \mathrm{~min}$ selected at random from total sleep time.

The observance was estimated by time-counter data and the report of night-by-night evaluation by the patients during the 3 week study period.

Clinical, polysomnographic and MWT results obtained at baseline and after the 3 week period of CPAP treatment were compared using a multivariate analysis of variance and Student's t-test, as homogeneity of variance and normality were encountered. In order to compare the results obtained in group I and group II and the effects of treatment, the different variables were compared by analysis of covariance of the changes from baseline, with baseline data as covariates. Sleep parameters were analysed using a multivariate analysis for repetitive measurements, since sleep stages represented dependant variables. The relative scattering of final MWT values in group II compared to group I was studied with an F-test for comparison of variance. Relationships between duration of CPAP use, clinical and polysomnographic variables, and final MWT were evaluated by Spearman rank correlations. Statistical significance was inferred for comparisons in which the p-value was $<0.05$. All values are presented as mean \pm SD.

\section{Results}

\section{Baseline sleep study}

The two groups were identical with respect to age (group I: $56 \pm 10$ yrs; group II: $53 \pm 8$ yrs) and BMI (group I: $34.8 \pm 4.1 \mathrm{~kg} \cdot \mathrm{m}^{-2}$; group II: $\left.31.0 \pm 4.4 \mathrm{~kg} \cdot \mathrm{m}^{-2}\right)$. Mean $( \pm \mathrm{sD})$ values for polysomnographic results in both groups are presented in table 1 . We did not find any significant differences in the sleep-related breathing disorders index between the two groups, with the same proportion of obstructive events in both groups (group I: $84.1 \pm 25.1 \%$; group II: $89.7 \pm 11.1 \%$ ). There was no difference in awake and nocturnal oxygen saturation characteristics between the two groups. The arousal index was similarly increased in both groups. The baseline sleep architecture is illustrated in figure 1 . There was a high percentage in light sleep associated with a low proportion of slow wave sleep in both groups, while REM sleep was close to the normal range.

The individual MWT values in both groups are illustrated in figure 2. Mean MWT values were similarly impaired without any significant difference between groups. Mean values for the ESQ and trail making tests A and B are presented in table 2 . There was no significant difference between groups.

\section{CPAP titration study}

For the whole study population, there was a significant difference between mean PFL and PAHS values (PFL: 10.4 \pm $2.6 \mathrm{cmH}_{2} \mathrm{O}$; PAHS $8.9 \pm 2.6 \mathrm{cmH}_{2} \mathrm{O}$; pressure difference $\left.(\Delta P)=1.55 \pm 1.04 \mathrm{cmH}_{2} \mathrm{O}, \mathrm{p}<0.01\right)$. On an individual basis, the difference between these two pressure levels reached $3 \mathrm{cmH}_{2} \mathrm{O}$ in four patients, $2 \mathrm{cmH}_{2} \mathrm{O}$ in five patients, and $1 \mathrm{cmH}_{2} \mathrm{O}$ in six patients. Three patients showed no difference between these two pressure levels. Mean $P$ eff value, defined as the level of pressure used during the study period in each group, was $9.3 \pm 1.4 \mathrm{cmH}_{2} \mathrm{O}$ in group I and $9.9 \pm 2.8 \mathrm{cmH}_{2} \mathrm{O}$ in group II $(\mathrm{p}>0.05)$.

Table 1. - Baseline and final mean ( $(\mathrm{SD})$ values for polysomnographic parameters in group I and in group II

\begin{tabular}{|c|c|c|c|c|c|c|}
\hline & $\begin{array}{c}\text { TST } \\
\mathrm{h}\end{array}$ & $\begin{array}{c}\text { Arousal index } \\
\mathrm{n} \cdot \mathrm{h}^{-1}\end{array}$ & $\begin{array}{c}\mathrm{A} / \mathrm{H} \text { index } \\
\mathrm{n} \cdot \mathrm{h}^{-1}\end{array}$ & $\begin{array}{c}{\mathrm{Sa}, \mathrm{O}_{2}, \mathrm{w}} \\
\%\end{array}$ & $\begin{array}{c}\mathrm{Sa}_{\mathrm{a}, \mathrm{O}_{2}, \min } \\
\%\end{array}$ & $\begin{array}{c}{\mathrm{Sa}, \mathrm{O}_{2}, \mathrm{~m}} \\
\%\end{array}$ \\
\hline \multicolumn{7}{|l|}{ Group I (n=9) } \\
\hline Baseline & $6.62 \pm 1.32$ & $49.6 \pm 28.7$ & $56.9 \pm 21.7$ & $96.2 \pm 2.4$ & $68.3 \pm 12.1$ & $91.2 \pm 1.3$ \\
\hline Final & $6.68 \pm 0.75$ & $7.9 \pm 3.8$ & $2.8 \pm 2.0$ & $96.7 \pm 1.7$ & $86.1 \pm 8.3$ & $95.2 \pm 1.8$ \\
\hline Between visits comparison & NS & $\mathrm{p}<0.01$ & $\mathrm{p}<0.01$ & NS & $\mathrm{p}<0.05$ & $\mathrm{p}<0.05$ \\
\hline \multicolumn{7}{|l|}{ Group II $(n=9)$} \\
\hline Baseline & $6.62 \pm 1.24$ & $50.4 \pm 24.3$ & $60.4 \pm 22.8$ & $95.6 \pm 3.1$ & $67.0 \pm 13.6$ & $91.8 \pm 4.0$ \\
\hline Final & $6.58 \pm 0.67$ & $7.5 \pm 3.9$ & $2.7 \pm 1.6$ & $96.2 \pm 1.7$ & $87.6 \pm 5.6$ & $95.3 \pm 1.6$ \\
\hline Between visits comparison & NS & $\mathrm{p}<0.01$ & $\mathrm{p}<0.01$ & NS & $p<0.05$ & $\mathrm{p}<0.05$ \\
\hline Between groups comparison & NS & NS & NS & NS & NS & NS \\
\hline
\end{tabular}

TST: total sleep time; Arousal index: number of arousals per hour; A/H index: number of apnoeas and hypopnoeas per hour; $S_{\mathrm{a}, \mathrm{O}_{2}}$ :

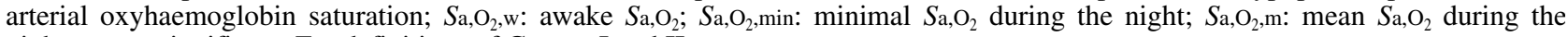
night; ns: nonsignificant. For definitions of Groups I and II, see text. 

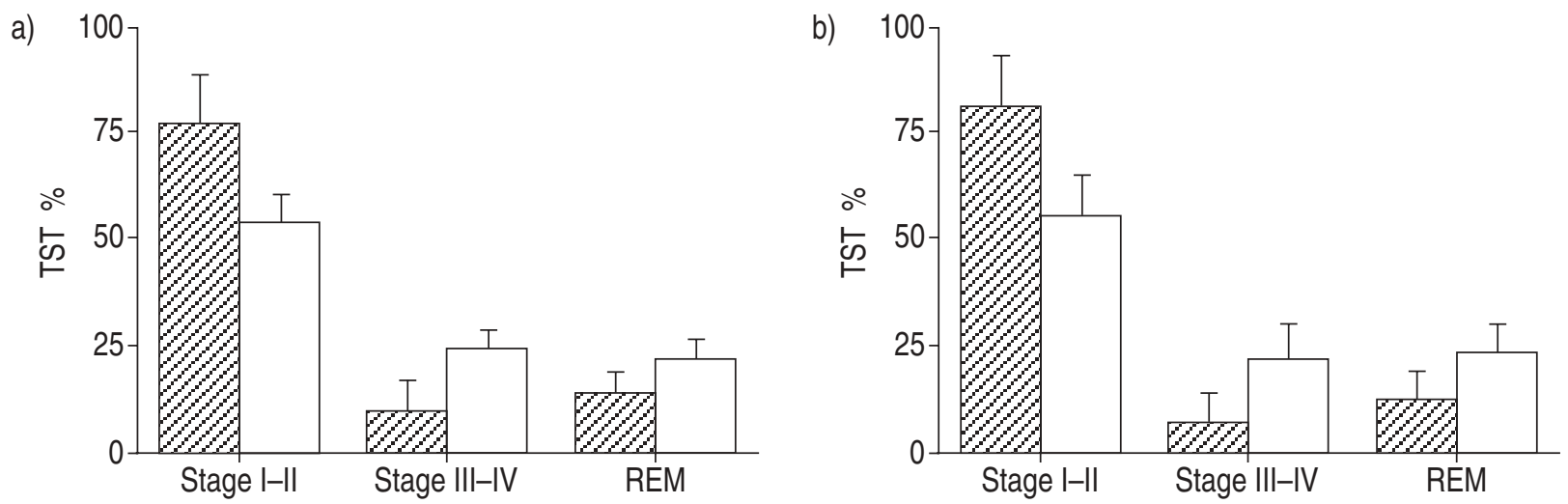

Fig. 1. - Sleep architecture during the initial and final polysomnographic studies in a) group I and b) group II. TST: total sleep time; Stage I-II: light sleep (stages I and II); Stage III-IV: deep sleep (stages III and IV); REM: rapid eye movement sleep. The values are expressed as a percentage of TST (mean \pm sD). $Z$ : initial value; $\square$ : final value.
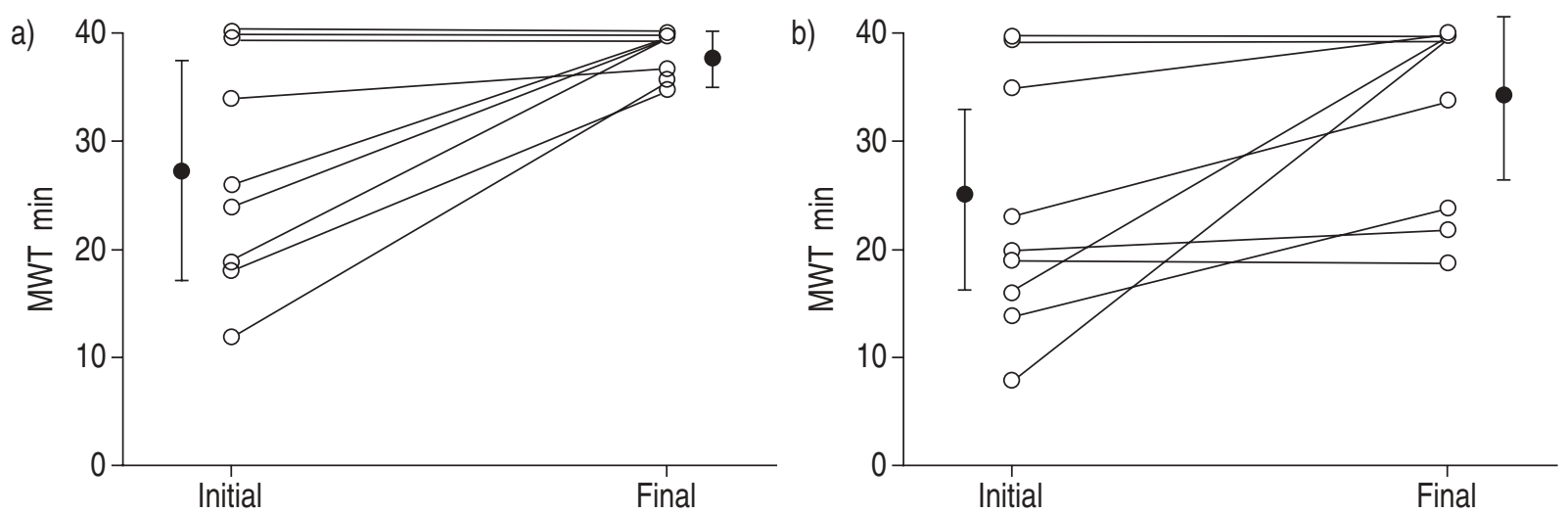

Fig. 2. - Individual (O) and mean ( \pm SD) ( $\bullet$ values of the sleep latency during the maintenance of wakefulness tests (MWT) at baseline (initial) and at the end of the study period (final) in a) group I and b) group II. The values are expressed in minutes.

\section{Home study period}

The duration of the treatment period was the same in both groups (group I: $19.9 \pm 1.8$ days; group II: $19.4 \pm 2.7$ days). We found a significant difference in the daily duration of nasal CPAP use between the two groups (group I: $7.29 \pm 0.95 \mathrm{~h} \cdot$ day $^{-1}$; group II: $6.01 \pm 0.94 \mathrm{~h} \cdot$ day $^{-1} ; \mathrm{p}=0.01$ ) despite identical initial recommendations for CPAP use being given to patients.

Table 2. - Baseline and final mean $( \pm S D)$ values for trail making tests and Epworth Sleep Questionnaire (ESQ), score in groups I and II

\begin{tabular}{lccc}
\hline & TMA & TMB & ESQ \\
& $\mathrm{s}$ & $\mathrm{s}$ & \\
\hline Group I ( $\mathrm{n}=9)$ & & & \\
$\quad$ Baseline & $57 \pm 18$ & $128 \pm 39$ & $12 \pm 4$ \\
$\quad$ Final & $41 \pm 13$ & $122 \pm 72$ & $4 \pm 4$ \\
Between visits comparison & $\mathrm{p}=0.02$ & $\mathrm{NS}$ & $\mathrm{p}<0.01$ \\
Group II ( $\mathrm{n}=9)$ & & & \\
$\quad$ Baseline & $47 \pm 20$ & $112 \pm 42$ & $13 \pm 4$ \\
$\quad$ Final & $32 \pm 9$ & $88 \pm 24$ & $4 \pm 3$ \\
Between visits comparison & $\mathrm{p}=0.02$ & $\mathrm{p}=0.02$ & $\mathrm{p}<0.01$ \\
Between groups comparison & $\mathrm{NS}$ & $\mathrm{NS}$ & $\mathrm{NS}$
\end{tabular}

The results of the trail making test A (TMA) and test B (TMB) are expressed in seconds, corresponding to the time needed to perform the tests. A normal value for ESQ would be below 9. For definitions of Groups I and II, see text.

\section{Final sleep study}

Final polysomnographic results in both groups are presented in table 1 and the evolution of sleep architecture is illustrated in figure 1. There was a significant improvement in all parameters between the initial and final recordings, for both groups. Sleep stages returned to normal values, while arousal and apnoea/hypopnoea indices were in the normal range, associated with a normalization of nocturnal oxygen saturation. Interestingly, there was no significant difference in these improvements between the two groups. The proportion of obstructive and nonobstructive events was similar between the two groups, with a lower percentage of obstructive events than at initial visit (group I: $56.2 \pm 45.4 \%$; group II: $65.8 \pm 44.1 \%$ ) at the benefit of central events (group I: $35.8 \pm 41.2 \%$; group II: $31.4 \pm 39.2 \%$ ). Interestingly, there was no significant difference in these improvements between the two groups. The final flow limitation index remained significantly higher in group II than in group I (group I: $24 \pm 11$ events $\cdot h^{-1}$; group II: $74 \pm 42$ events $\left.\cdot \mathrm{h}^{-1} ; \mathrm{p}<0.05\right)$.

The number of arousals and microarousals was identical in both groups. No correlation was found between any of these parameters and the number of flow-limited respiratory cycles (table 3 ). The mean and maximal oesophageal pressure values were higher for the $30 \mathrm{~min}$ of discontinuous sleep analysed in group II than in group I, but this difference did not reach significance when analysed between 
Table 3. - Spontaneous and flow limitation-related (provoked) arousals and micro-arousals in groups I and II during the final polysomnography

\begin{tabular}{lcccc}
\hline & $\begin{array}{c}\text { Spon. } \\
\text { arousals }\end{array}$ & $\begin{array}{c}\text { Prov. } \\
\text { arousals }\end{array}$ & $\begin{array}{c}\text { Spon. } \\
\text { micro- } \\
\text { arousals }\end{array}$ & $\begin{array}{c}\text { Prov. } \\
\text { micro- } \\
\text { arousals }\end{array}$ \\
\hline Group I $(\mathrm{n}=9)$ & $4.2 \pm 1.9$ & $2.4 \pm 2.1$ & $2.9 \pm 3.9$ & $0.2 \pm 0.4$ \\
$\begin{array}{l}\text { Group II }(\mathrm{n}=9) \\
\begin{array}{c}\text { Between groups } \\
\text { comparison }\end{array}\end{array}$ & $3.0 \pm 2.2$ & $3.8 \pm 4.4$ & $1.2 \pm 1.1$ & $2.1 \pm 2.5$ \\
NS & NS & NS & NS
\end{tabular}

The values are expressed as mean \pm SD from the total number of events, calculated in each patient throughout the 30 randomly selected 1 min epochs. Spon.: spontaneous; Prov.: provoked. ns: nonsignificant.

Table 4. - Total number of flow limited respiratory cycles and mean $( \pm S D)$ oesophageal pressure values (mean and maximal values) in groups I and II during the final polysomnography, calculated throughout the 30 randomly selected 1 min epochs in each sleep stage

\begin{tabular}{|c|c|c|c|}
\hline & $\begin{array}{c}\text { Group I } \\
(\mathrm{n}=6)\end{array}$ & $\begin{array}{c}\text { Group II } \\
(\mathrm{n}=6)\end{array}$ & $\begin{array}{l}\text { Between } \\
\text { group } \\
\text { comparison }\end{array}$ \\
\hline \multicolumn{4}{|l|}{$\overline{\text { REM sleep }}$} \\
\hline Flow-limited cycles & 51 & 119 & $\mathrm{p}<0.001$ \\
\hline$P$ mean $\mathrm{cmH}_{2} \mathrm{O}$ & $6.9 \pm 2.1$ & $6.6 \pm 2.4$ & NS \\
\hline$P \max \mathrm{cmH}_{2} \mathrm{O}$ & $9.1 \pm 2.7$ & $9.1 \pm 3.9$ & NS \\
\hline \multicolumn{4}{|l|}{ Stages I-II } \\
\hline Flow-limited cycles & 143 & 513 & $\mathrm{p}<0.0001$ \\
\hline$P$ mean $\mathrm{cmH}_{2} \mathrm{O}$ & $8.3 \pm 2.1$ & $9.8 \pm 4.8$ & NS \\
\hline$P_{\max } \mathrm{cmH}_{2} \mathrm{O}$ & $10.4 \pm 2.6$ & $12.4 \pm 5.8$ & NS \\
\hline \multicolumn{4}{|l|}{ Stages III-IV } \\
\hline Flow-limited cycles & 83 & 222 & $\mathrm{p}<0.001$ \\
\hline$P$ mean $\mathrm{cmH}_{2} \mathrm{O}$ & $8.0 \pm 2.7$ & $9.6 \pm 4.8$ & NS \\
\hline$P \max \mathrm{cmH}_{2} \mathrm{O}$ & $9.8 \pm 3.1$ & $11.7 \pm 5.8$ & NS \\
\hline
\end{tabular}

Ns: nonsignificant.

the different sleep stages (table 4). However, there was a positive correlation between both oesophageal pressure values and the number of flow limited cycles in each selected epoch $(\mathrm{p}<0.0001 ; \mathrm{r}=0.49)$ without any significant correlation between oesophageal pressure characteristics and final MWT values.

The changes in individual MWT values associated with CPAP therapy between initial and final studies are illustrated in figure 2. Although a significant improvement of mean MWT value was observed in both groups, without any significant difference between groups, the two groups were different in terms of variance, with a significantly greater scattering of final MWT values in group II $(\mathrm{p}<$ 0.001 ). Mean values for the ESQ and trail making tests A and $\mathrm{B}$ are presented in table 2 . There was no significant difference between the two groups for these parameters. However, although there was a similar significant improvement in the ESQ and trail making test A in the two groups, trail making test B significantly decreased only in group II. The absence of a significant difference between initial and final TMB values in group I can be explained by an increase in TMB value between initial and final studies in one patient of group I (from $130 \mathrm{~s}$ to $278 \mathrm{~s}$ ) while other patients in both groups presented a decrease in TMB value. This was responsible for the wide standard deviation in TMB values in group I at the final visit. If this patient was discarded from statistical analysis, the mean

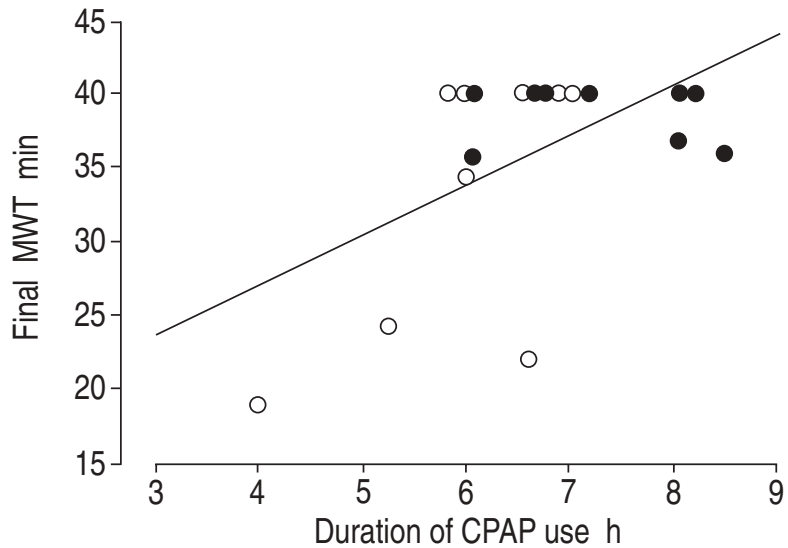

Fig. 3. - Individual values of the relationship between the sleep latency during the final maintenance of wakefulness tests (MWT) and the duration of continuous positive airway pressure (CPAP) use during the home study period in group I $(\bullet)$ and in group II ( O ).

TMB value in group I decreased significantly (initial study: $127 \pm 42 \mathrm{~s}$; final study: $99 \pm 38 \mathrm{~s} ; \mathrm{p}=0.04$ ) and these values were similar to those in group II.

In group II, where patients were treated at PAHS, there was no correlation between final MWT values and the am-plitude of the difference between PAHS and PFL. More-over, there was no correlation between MWT values and polysomnographic parameters, arousal, and apnoea/ hypo-pnoea indices, and the index of flow limited respiratory cycles at baseline or at the end of the treatment period for the entire study group. A positive correlation was found between final MWT values and the duration of CPAP use for all patients $(\mathrm{p}<0.05 ; \mathrm{r}=0.55)$ (fig. 3 ).

\section{Discussion}

Our study demonstrated that determining the effective pressure level for the suppression of flow limitation did not improve the efficiency of nasal CPAP with regard to sleep quality and sleep-related breathing disorders compared to conventional $P$ eff determination based on the disappearance of apnoea, hypopnoea and snoring. However, although a significant subjective improvement in daytime vigilance occurred in both groups, the analysis of MWT changes demonstrated a significantly greater scattering of final values when flow limitation was not suppressed by nasal CPAP, corresponding to a less homogeneous improvement of objective daytime performances in this case.

The present results demonstrate the influence of the parameters taken into account to determine the efficient pressure level in the treatment of SAHS. HOFFSTEIN and MАтЕIKA [19] proposed an equation to predict the optimal level of CPAP that prevents sleep apnoea by using parameters such as BMI, neck circumference, and apnoea/ hypopnoea index, which induced a reduction in apnoea/ hypopnoea index below 10 events. $h^{-1}$. However, there was no information concerning the efficiency with which this estimated pressure would suppress snoring, and the evolution of daytime vigilance was not considered. Beneficial effects of nasal CPAP have been widely described in patients receiving an efficient pressure level that eliminated snoring and obstructive sleep respiratory disorders [9, 20]. Moreover, Guilleminault et al. [21] reported the frequent 
association of snoring with transient arousals leading to sleep fragmentation and daytime somnolence. These short arousals were directly related to an abnormal increase in respiratory efforts during sleep that occurred within several breaths of flow limitation. This has led to the determination of the efficient pressure based on the normalization of respiratory efforts [10] or flow limitation [11]. However, in the latter study flow limitation was visually detected according to the contour of the inspiratory flow tracing, while the definition of flow limitation usually involved analysis of the oesophageal pressure [16], which is an invasive method that may be difficult to use in clinical practice.

In our study, despite the absence of a significant difference in mean final MWT values between the two groups, the analysis of variance showed that choosing PAHS as the effective pressure was associated with a more important dispersion in individual values than when CPAP was used at PFL level. This was associated with an absence of improvement in three patients from group II whose MWT remained at a low value. It is debatable to what extent our results may be the consequence of the spontaneous variability of the neuropsychological response to CPAP therapy. However, it must be emphasized that this inhomogeneity in the interindividual clinical response differed significantly between the two treatment groups, and that this difference was observed even with a small study population. There is no doubt that such a study design, with a breathby-breath analysis of flow limitation, cannot be carried out in a large SAHS sample. Therefore, although our study does not have the statistical power of a large clinical trial, it does have the benefits of a straightforward capacity for detection analysis and correction of flow-limited breaths. The differences in clinical response observed between the two treatment groups could not be explained by the individual differences between PAHS and PFL levels since no correlation was found in group II between final MWT values and the amplitude of this difference. Therefore, the absence of improvement in MWT following CPAP therapy cannot be accounted for by the greatest differences between $P$ AHS and $P$ FL during the study period.

Moreover, for the study population as a whole, we did not find any correlation between final MWT and arousal index, apnoea/hypopnoea index, nocturnal $\mathrm{Sa}_{\mathrm{a}} \mathrm{O}_{2}$ parameters or sleep stages distribution. The only difference observed between the two groups concerned the daily CPAP use and the remaining index of flow limited respiratory cycles. According to the positive correlation that we found between final MWT and the duration of CPAP use, the lower daily observance in group II could account for the partial improvement in objective daytime vigilance found in this group. We can only speculate on the possible factors that accounted for the better observance of CPAP therapy in group I. It would be surprising that, despite the initial randomization, this difference in CPAP observance could be related simply to hazard and it is more likely that it could be explained by another factor such as the persistence of an elevated upper airway resistance. This hypothesis may be advocated since we found a significantly higher number of residual flow-limited respiratory cycles in group II at the end of the study period. Even if flow limitation is a normal feature of nocturnal breathing, and occurs also in nonsnoring patients [22], we found that a higher number of residual flow-limited respiratory cycles was associated with higher oesophageal pressure, particularly in non-REM sleep, with a positive correlation between both oesophageal pressure values and the number of flow-limited cycles. It could be hypothesized that this persistence of increased inspiratory efforts could be associated with residual arousals leading to sleep fragmentation and diurnal hypovigilance. This hypothesis is not definitively in opposition to the normalization of the arousal index observed in group II, since it only reflects the inability to clearly assess sleep fragmentation by the current arousal scoring rules [23]. Even if we did not find any link between micro-arousals and either flow limitation or MWT, the quantification of sleep microarchitecture with the aid of spectral analysis would be helpful in confirming this hypothesis.

In conclusion, these results tend to promote the necessity to detect and correct residual flow limitation in case of persistent daytime hypovigilance during continuous positive airway pressure therapy using a classical determination of efficient pressure fixed on the regression of apnoea, hypopnoea and snoring, even if the mechanisms underlying this hypothesis are not clearly demonstrated.

Acknowledgements: The authors would like to thank P. Ingrand (Dept of Medical Statistics, Poitiers) for his collaboration, and R. Prendergast for his linguistic assistance.

\section{References}

1. He J, Kryger MH, Zorick FJ, Conway W, Roth T. Mortality and apnea index in obstructive sleep apnea. Chest 1988; 94: 9-14.

2. Partinen M, Guilleminault C. Daytime sleepiness and vascular morbidity at seven-year follow-up in obstructive sleep apnea patients. Chest 1990; 97: 27-32.

3. Kales A, Caldwell AB, Cadieux RJ, Vela-Bueno A, Ruch LG, Mayes SD. Severe obstructive sleep apnea: associated psychopathology and psychosocial consequences. $J$ Chron Dis 1985; 38: 427-434.

4. Millman RP, Fogel BS, McNamara ME, Carlisle CC. Depression as a manifestation of obstructive sleep apnea: reversal with nasal continuous positive airway pressure. $J$ Clin Psychiatry 1989; 50: 348-351.

5. Sullivan CE, Issa FQ, Berthon-Jones M, Eves L. Reversal of obstructive sleep apnea by continuous positive airway pressure applied through the nares. Lancet 1981; 1: 862865.

6. Derderian SS, Bridenbaugh H, Rajagopal KR. Neuropsychologic symptoms in obstructive sleep apnea improve after treatment with nasal continuous positive airway pressure. Chest 1988; 94: 1023-1027.

7. Sanders MH. Nasal CPAP effect on patterns of sleep apnea. Chest 1984; 86: 829-844.

8. Sforza E, Krieger J, Weitzenblum E, Apprill M, Lampert $\mathrm{E}$, Ratamahaharo J. Long term effects of treatment with nasal continuous positive airway pressure on daytime lung function and pulmonary hemodynamics in patients with obstructive sleep apnea. Am Rev Respir Dis 1990; 141: 866-870.

9. Leech JA, Onal E, Lopata M. Nasal CPAP continues to improve sleepdisordered breathing and daytime oxygenation over long term follow-up of occlusive sleep apnea syndrome. Chest 1992; 102: 1651-1655.

10. Sforza E, Krieger J, Bacon W, Petiau C, Zamagni M, Boudewins A. Determinants of effective continuous positive 
airway pressure in obstructive sleep apnea. Am J Respir Crit Care Med 1995; 151: 1852-1856.

11. Condos R, Norman RG, Krishnasamy I, Peduzzi N, Goldring RM, Rapoport D. Flow limitation as a non invasive assessment of residual upper-airway resistance during continuous positive airway pressure therapy of obstructive sleep apnea. Am J Respir Crit Care Med 1994; 150: 475480.

12. Poceta JS, Timms RM, Jeong DU, Ho JL, Erman MK, Mitler MM. Maintenance of wakefulness test in obstructive sleep apnea syndrome. Chest 1992; 101: 893-897.

13. Reitan RM. Validity of the trail making test as an indicator of organic brain damage. Percept Motor Skills 1958; 8: 271-276.

14. Johns MW. Daytime sleepiness, snoring, and obstructive sleep apnea. The Epworth sleepiness scale. Chest 1993; 103: 30-36.

15. Liistro G, Stanescu DC, Veriter C, Rodenstein DO, Aubert- Tulkens G. Pattern of snoring in obstructive sleep apnea patients and in heavy snorers. Sleep 1991; 14: 517525.

16. Schwartz AR, Smith PL, Wise RA, Gold AR, Permutt S. Induction of upper airway occlusion in sleeping individuals with subatmospheric nasal pressure. J Appl Physiol 1988; 64: 535-542.
17. Rechtschaffen A, Kales A. A manual of standardised terminology, techniques and snoring system for sleep stages of human subjects. Washington D.C.; Public Health Service, 1968. National Institutes of Health publication 204.

18. American Sleep Disorders Association. EEG arousals: scoring rules and examples. Sleep 1992; 15: 174-183.

19. Hoffstein V, Mateika S. Predictive nasal continuous positive airway pressure. Am J Respir Crit Care Med 1994; 150: 486-488.

20. Ryan CF, Lowe AA, Li D, Fleetham JA. Magnetic resonance imaging of the upper airway in obstructive sleep apnea before and after chronic nasal continuous positive airway pressure therapy. Am Rev Respir Dis 1991; 144: 939-944.

21. Guilleminault C, Stoohs R, Clerk A, Cetel M, Maistros P. A cause of excessive daytime sleepiness: the upper airway resistance syndrome. Chest 1993; 104: 781-787.

22. Rapoport DM, Norman RG, Krishnasamy I, Wasleben JA. Flow limitation during sleep in normal subjects. Am J Respir Crit Care Med 1994; 149: A493.

23. Martin SE, Wraith PK, Deary IJ, Douglas NJ. The effect of non visible sleep fragmentation on daytime function. Am J Respir Crit Care Med 1997; 155: 1596-1601. 